\title{
Evaluation of mental foramen - A CBCT assessment
}

\author{
Gareema Raju ${ }^{1, *}$, V. Sairam², Geethamalika ${ }^{3}$, Vikas ${ }^{4}$, Suguna $^{5}$ \\ ${ }^{1,4}$ Senior Lecturer, ${ }^{2}$ Professor \& HOD, ${ }^{3}$ Ex PG Student, ${ }^{5}$ PG Student, Dept. of Oral Medicine and Radiology, G. Pulla Reddy \\ Dental College and Hospital, Dr. NTR University of Health Sciences, Kurnool, Andhra Pradesh, India
}

*Corresponding Author:

Email: gareemaraju06@gmail.com

\begin{abstract}
The knowledge on the anatomic characteristics and variations of Mental Foramen is very important in surgical procedures involving that area. The mental nerve may be injured during local anesthesia, endodontic treatment and other oral surgical procedures.

Aim of the study: The study performed aimed at assessing position of the MF relative to the apices of the teeth and MF to lingual cortex and to the base of the mandible

Materials and Methods: The study was conducted using Care stream 9100 select CBCT machine on 50 patients. Measurements were made from the edges of the mental foramen to the lingual cortex, and to the base of the mandible. The inferential statistics were performed using "independent t-test" and the p-value $(<0.05)$ was calculated using the same. The statistics were performed using SPSS 20 software.

Results: In terms of the location of mental foramen, it is most commonly found in the line of long axis of $2^{\text {nd }}$ premolar. In case of measurements of mental foramen from the lingual cortex and lower body of mandible, the lingual edge of MF to lingual cortex was located, on average of $3.3 \mathrm{~mm}$ in males and $3.8 \mathrm{~mm}$ in females and the lower edge of the MF was located, $8.4 \mathrm{~mm}$ (males) \& $7.1 \mathrm{~mm}$ (females) from the lower edge of mandible.

Conclusion: The location of the mental foramen greatly influences the surgical planning .Hence there is need and importance of studies involving the anatomical characteristics of the mental foramen, which permit procedures to the performed more safely on the mandible.
\end{abstract}

\section{Introduction}

The mental foramen is a funnel-like opening located on the surface of the anterolateral aspect of the mandible. ${ }^{1}$ It marks the termination of the mandibular canal in the mandible, through which the inferior alveolar nerve and vessels pass. Themandibular canal bifurcates at the foramen, forming the mental and incisive canals, which supply sensory innervation and blood supply to the soft tissues of the chin, lower lip and gingiva on the ipsilateral side of the mandible. ${ }^{2}$

Regarding the location of the mental foramen, there is considerable anatomical variation in the vertical and horizontal planes. ${ }^{3}$ Although the region between the mental foramen and the mandible is considered a safe region for surgical procedures such as the removal of bone graft, placement of plates for the fixation of fractures, mentoplasty, orthognathic surgery and placement of osseointegratable implants, it presents a risk of injury to the neurovascular structures. ${ }^{4}$

Hence the knowledge on the anatomic characteristics and variations of mental foramen is very important in surgical procedures involving that area.

\section{Materials and Methods}

A study was conducted using carestream 9100 select cone beam computed tomography machine on a total of 50 CBCT projections including both right and left sides of the mandible (bilateral). The study aimed at locating the exact position of the MF relative to the apices of the teeth and to determine the location of mental foramen from the lingual cortex and the base of the mandible.

The study was performed with the visualization of the images in the panoramic and coronal reconstructions.

In the panoramic reconstruction, the mental foramen was analyzed according to the classification system proposed by Chkoura, El Wady ${ }^{5}$ in 6 categories: 1) before the long axis of the first lower premolar, 2) in line with the long axis of the first lower premolar, 3) between the long axis of the first and second lower premolars, 4) in line with the long axis of the second lower premolar, 5) between the long axis of the second lower premolar and the first lower molar, and 6) in line with the long axis of the mesial root of the first lower molar

The measurements performed in the study were made in the coronal reconstructions, from the region where the hypodensity corresponding to the opening of the mental foramen could be observed to the external edge to the lingual cortices and base of the mandible respectively (Fig. 2).

The data obtained was then statistically analysed through an "independent t-test" by using SPSS 20 software. 


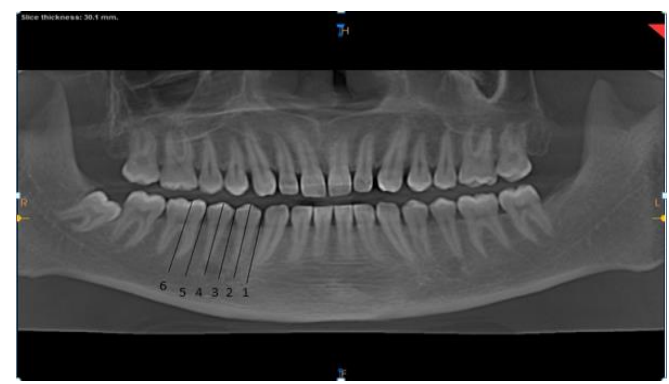

Chkoura, EL Wady13, P. 72

Fig. 1: Schematic representation of the numeric expression of the position of the mental foramen relative to the tooth

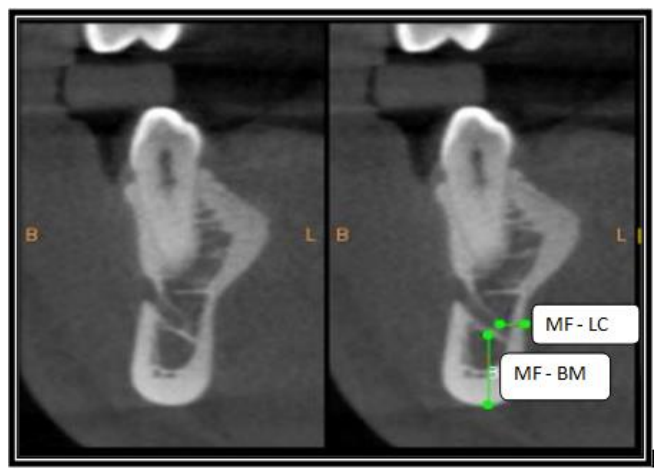

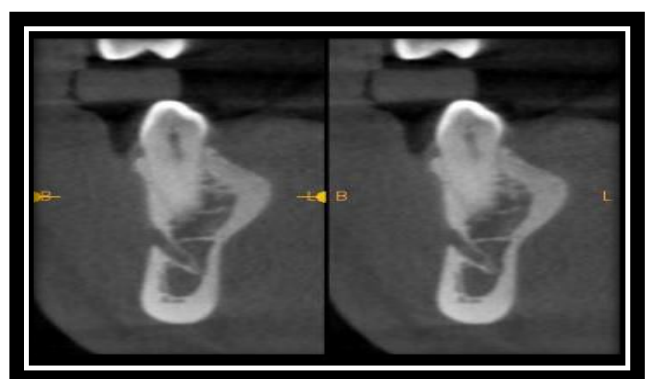

Fig. 2: The figure represents the measurements from mental foramen (mf) to the external edge to the Lingual Cortices (LC) and base of the mandible (BM)

\section{Results}

In the present study the location of the mental foramen was most commonly found in the line of long axis of $2^{\text {nd }}$ premolar.

In case of frequency of position of mental foramen, the mental foramen was located mainly below the second pre-molar $(45 \%)$ on left side and on right side it is below the line in between $1^{\text {st }} \& 2^{\text {nd }}$ premolar $(44 \%)$. (Table 1)

In terms of individual measurements the lingual edge of MF to lingual cortex was located, on average of $3.3 \mathrm{~mm}$ in males and $3.8 \mathrm{~mm}$ in females and with regards to the lower edge of the MF to the lower edge of mandible the measurements were found to be $8.4 \mathrm{~mm}$ in males whereas $7.1 \mathrm{~mm}$ in females. (Table 2)

In our study the distance from the mental foramen to the lingual cortex was found to be be 3.38 (males) and 3.61(females) along the right side and 3.40(males) and 4.055 (females) along the left side. (Table 3)

In case of distance from the mental foramen to the lower border of the mandible the measurements were found to be 8.49 (males) and 7.004(females) along the right side and 8.49 (males) and 7.29(females) along the left side. (Table 3)

Table 1: The table denotes frequency of position of MF (PML- PREMOLAR, ML- MOLAR, LA-LONG AXIS, MR-MESIAL ROOT)

\begin{tabular}{|l|c|c|c|c|c|c|}
\hline \multicolumn{1}{|c|}{ Location } & Right & $(\boldsymbol{\%})$ & Left & $\mathbf{( \% )}$ & Total & $\mathbf{( \% )}$ \\
\hline $\begin{array}{l}\text { Before the } \\
\text { LA of the } \\
\text { 1PML }\end{array}$ & 0 & 0 & 0 & 0 & 0 & 0 \\
\hline $\begin{array}{l}\text { In line with } \\
\text { the LA of the } \\
\text { 1PML }\end{array}$ & 0 & 0 & 1 & 2 & 1 & 1 \\
\hline $\begin{array}{l}\text { Between the } \\
\text { LA of the } \\
\text { 1PML and } \\
\text { 2PML }\end{array}$ & 22 & 44 & 20 & 40 & 42 & 42 \\
\hline $\begin{array}{l}\text { In line with } \\
\text { the LA of the } \\
\text { 1PML }\end{array}$ & 21 & 42 & 24 & 48 & 45 & 45 \\
\hline $\begin{array}{l}\text { Between the } \\
\text { LA of the }\end{array}$ & 5 & 10 & 5 & 10 & 10 & 10 \\
\hline
\end{tabular}




\begin{tabular}{|l|c|c|c|c|c|c|}
\hline $\begin{array}{l}\text { 2PML and } \\
\text { 1PML }\end{array}$ & & & & & & \\
\hline $\begin{array}{l}\text { In line with } \\
\text { the LA of the } \\
\text { MR of 1ML }\end{array}$ & 2 & 4 & 0 & 0 & 2 & 2 \\
\hline Total & 50 & 100 & 50 & 100 & 100 & 100 \\
\hline
\end{tabular}

Table 2: The table denotes the measurements from the Mental Foramen (MF) to the external edge to the lingual cortices (LC) and base of the mandible (BM) in both males and females

\begin{tabular}{|c|l|c|c|c|c|}
\hline \multirow{2}{*}{ Sex } & & N & Mean & $\begin{array}{c}\text { STD } \\
\text { Deviation }\end{array}$ & P Value \\
\hline \multirow{2}{*}{ MF-LC } & Male & 64 & 3.3969 & 1.457 & 0.144 \\
\cline { 2 - 5 } & Female & 36 & 3.8333 & 1.3556 & \\
\hline \multirow{2}{*}{ MF-BM } & Male & 64 & 8.4953 & 1.568 & 0.000 \\
\cline { 2 - 5 } & Female & 36 & 7.1500 & 1.338 & \\
\hline
\end{tabular}

Table 3: The table denotes the measurements from the Mental Foramen (MF) to the external edge to the lingual cortices (LC) and base of the mandible (BM) in both males and females along right as well as left side

\begin{tabular}{|l|l|l|c|c|c|c|}
\hline \multicolumn{2}{|c|}{} & \multicolumn{1}{|c|}{ Sex } & N & Mean & $\begin{array}{c}\text { STD } \\
\text { Deviation }\end{array}$ & $\begin{array}{c}\text { P } \\
\text { Value }\end{array}$ \\
\hline \multirow{3}{*}{ Right } & \multirow{2}{*}{ MF-LC } & Male & 32 & 3.38 & 1.528 & 0.602 \\
\cline { 3 - 7 } & & Female & 18 & 3.61 & 1.337 & \\
\cline { 3 - 6 } & \multirow{2}{*}{ MF-BM } & Male & 32 & 8.49 & 1.435 & 0.001 \\
\cline { 3 - 6 } & Female & 18 & 7.005 & 1.457 & \\
\hline \multirow{3}{*}{ Left } & \multirow{2}{*}{ MF-LC } & Male & 32 & 3.40 & 1.406 & \multirow{2}{*}{0.122} \\
\cline { 3 - 6 } & & Female & 18 & 4.055 & 1.374 & \\
\cline { 3 - 6 } & \multirow{2}{*}{ MF-BM } & Male & 32 & 8.49 & 1.714 & \multirow{2}{*}{0.012} \\
\cline { 3 - 6 } & & Female & 18 & 7.29 & 1.233 & \\
\hline
\end{tabular}

\section{Discussion}

In the present study, the mental foramen was located mainly below the second pre-molar $(45 \%)$ on left side and on right side it was found below the line in between $1^{\text {st }} \& 2^{\text {nd }}$ premolar (44\%). It was in accordance with the studies performed by Saito et al. ${ }^{4}$, Leila et al., ${ }^{6}$ Haghanifar $\mathrm{S}$ et al. ${ }^{7}$ and Gupta $\mathrm{S}$ et al.

Saito et al. ${ }^{4}$ found about $45 \%$ of the mental foramina were located in the apex of the second premolar. Similar findings were recorded by Leila et al. ${ }^{6}$ who performed a study, using 158 CBCT images and Haghanifar S et al., ${ }^{7}$ who evaluated 400 panoramic radiographs with regard to the location and symmetry of the mental foramina and found that in $49.2 \%$ of radiographs, MF was in line with the second premolar.

Our study also showed positive correlation with the study performed by Gupta $\mathrm{S}$ et al., ${ }^{8}$ who found that MF was situated below the apex of 2 nd premolar tooth in $75.8 \%$ of mandibles, whereas in $12.2 \%$ of mandibles it was situated between 1st and 2nd premolars.

In terms of location, the MF was located, on average of $3.3 \mathrm{~mm}$ in males and $3.8 \mathrm{~mm}$ in females from the lingual cortex of the mandible. This findings correlated with the studies performed by Saito et al. ${ }^{4}$ and Pyun et al, ${ }^{9}$ wherein Saito et al. ${ }^{4}$ found that the lingual edge was located, on average, $3.1 \mathrm{~mm}$ from the lingual cortex, with no statistically significant influence with age or sex had and Pyun et al., ${ }^{9}$ who conducted a study to investigate the deviation of the buccolingual pathway from the mandibular canal and the relationship with the location of the mental foramen found a mean value of $5.60 \mathrm{~mm}$ of the buccolingual measurements, using computerized tomography and the most common location of MF was along the long axis of $2^{\text {nd }}$ premolar. Their results were larger than those of the present study as they measured from the center of the mandibular canal to the lingual cortex of the mandible.

With regard to the distance between mental foramen and lower body of mandible, Yesilyurt et al. ${ }^{10}$ performed a study to investigate the possible local differences of the mental foramen in Eastern Anatolian individuals in the Turkish population and found the distance from the inferior border of the foramen to the lower border of the mandibular body to be $9.44 \mathrm{~mm}$ and $9.46 \mathrm{~mm}$ along the right and left side respectively. These findings were in correlation with our study where the distance from the inferior border of the foramen to the lower border of the mandible were found to be 8.49 (males) and 7.004(females) along the right side and 8.49(males) and 7.29(females) along the left side.

In case of the measurement of MF above the lower edge of mandible, it was found to be located on average of $8.4 \mathrm{~mm}$ (males) \& $7.1 \mathrm{~mm}$ (females) which was similar to the study performed by Saito et al., ${ }^{4}$ who found a mean value of $7.9 \mathrm{~mm}$ (males) \& $7 \mathrm{~mm}$ (females), in $100 \mathrm{CBCT}$ images. Age had no 
statistically significant influence $(p=0.5109)$, but sex was found to have statistical significant $(\mathrm{p}=0.0001)$.

Similar assessment was made by Ashwinirani $\mathrm{S}$ et al, ${ }^{11}$ and Lorenzo et al. ${ }^{12}$. Ashwinirani $S$ et al, ${ }^{11}$ found the average distance from IMF to LBM in males was $11.8 \mathrm{~mm}$ and in females $11.4 \mathrm{~mm}$ with comparison between the genders showing high statistically significant differences.

On comparison with the study performed by Lorenzo et al. ${ }^{1,2}$ who evaluated a sample of 344 CBCT scans for presence and characteristics (i.e. diameter, area, shape, exit angle) of MF \& AMF. They found the MF-MIB distance to be $13.55 \pm 1.06 \mathrm{~mm}$, with statistical significance in terms of gender determination.

\section{Conclusion}

CBCT is an effective tool for three-dimensional assessment of Mental Foramen (MF), which is an important anatomic landmark in dentistry. As the location of the mental foramen has profound influence during anesthesia and surgical implant planning, it is suggested that there is need and importance of further studies involving the anatomical characteristics of the mental foramen in specific populations which permits procedures to be performed more safely on the mandible.

\section{References}

1. Thakare S, Mhapuskar A, Hiremutt D, Giroh V, Kalyanpur K, Alpana K. Evaluation of the Position of Mental Foramen for Clinical and Forensic Significance in terms of Gender in Dentate Subjects by Digital Panoramic Radiographs. The Journal of Contemporary Dental Practice. 2016;17(9):762-8.

2. Ngeow WC and Yuzawati Y. The location of the mental foramen in a selected Malay population. Journal of Oral Science.2003;45(3):171-5.

3. Parnami P, Gupta D, Arora V, Bhalla S, Kumar A, Malik R. Assessment of the Horizontal and Vertical Position of Mental Foramen in Indian Population in Terms of Age and Sex in Dentate Subjects by Pano-ramic Radiographs: A Retrospective Study with Review of Literature. Open Dent J. 2015 Jul 31;9:297-302. doi: 10.2174/1874210601509010297.

4. Saito, Araujo, Saito et al. Analysis of the mental foramen using cone beam computerized tomography. Rev Odontol UNESP. 2015 July-August;44(4):226-31.

5. Chkoura A, El Wady W. Position of the mental foramen in a Moroccan population: a radiographic study. Imaging Sci Dent. 2013;43(2):71-5.

6. Khojastepour L, Mirbeigi S, Mirhadi, and Ateieh Safaeeb. Location of Mental Foramen in a Selected Iranian Population: A CBCT Assessment. Iran Endod J. 2015;10(2):117-21.

7. Haghanifar S, Rokouei M. Radiographic evaluation of the mental foramen in a selected Iranian population. Indian J Dent Res 2009;20:1502.

8. Gupta S, Soni JS. Study of anatomical variations and incidence of mental foramen and accessory mental foramen in dry human mandibles.2012;2(1):28-30.

9. Pyun et al. Position of the mental foramen on panoramic radiographs and its relation to the horizontal course of the mandibular canal: a computed tomographic analysis. Clin. Oral Impl. Res. 24, 2013 / 890-5.

10. Yesilyurt H, Aydinlioglu A, Kavakli A, Ekinci N, Eroglu C, Hacialiogullari M, Diyarbakirli S. Local differences in the position of the mental foramen. Folia Morphol (Warsz). 2008;67(1):32-5.

11. Ashwinirani S, Suragimath G, Christopher V, Bijjargi S, Pawar R, Nayak A. Gender determination by radiographic analysis of mental foramen in the Maharashtra population of India. Journal of Forensic Dental Sciences. 2016;8(3):176.

12. Muinelo-Lorenzo J, Suárez-Quintanilla JA, FernándezAlonso A, Varela-Mallou J, Suárez-Cunqueiro MM. Anatomical characteristics and visibility of mental foramen and accessory mental foramen: Panoramic radiography vs. cone beam CT. Med Oral Patol Oral Cir Bucal. 2015 Nov 1;20 (6):e707-14. 